\title{
Combined Effect Of Nozzle- Dispersion Device On Spray Pattern Uniformity For Low Pressure Sprinklers
}

ESJ Natural/Life/Medical Sciences

\section{Zakaria Issaka,}

Department of Agricultural Engineering, Tamale Technical University, Northern Region, Ghana

\section{Alexander Fordjour,}

Department of Civil Engineering, Koforidua Technical University, Eastern Region, Ghana

\section{Ajani Adetunji Ibrahim,}

Department of Mechanical Engineering, Koforidua Technical University, Eastern Region, Ghana

Submitted: 08 June 2020

Accepted: 02 September 2020

Published: 31 October 2020

Corresponding author:

Zakaria Issaka

DOI: 10.19044/esj.2020.v16n30p145

(c)

Copyright 2020 Issaka et al.

Distributed under Creative Commons CC-BY 4.0 OPEN ACCESS

\section{Abstract}

An impact sprinkler with a newly designed nozzle-dispersion device and R33 sprinkler were introduced in this study. Comparative experiments and analyses on uniformity patterns of impinging water jet from both sprinklers were investigated by using high-speed photographic technique to visualize the spray. A mathematical model of the spray was developed and applied in MatLab to determine the spray angles at different axial distances. Results showed that the impact sprinkler with the nozzledispersion device combination gave the largest spray range of $12.6 \%$ larger than the R33 sprinkler. Combined effect of the nozzle-dispersion device for the impact sprinkler had a strong effect on the spray angle which increased with increasing pressure. Spray characteristics for the impact sprinkler were similar to those produced by the R33 sprinkler. The number of droplets increased with increasing spray angle due to early breakup of the jet, which is beneficial for greater water dispersion and uniformity. It was found that a low working pressure of $150 \mathrm{kPa}$ leads to lower degree of nonuniformities for the sprinklers, and the variation coefficient were less than $10 \%$. Obtained mathematical models of the changes in the variation coefficient was dependent upon working pressure and can be a good basis for easy management of the parameters necessary for the uniform spray distribution. Hence, the impact sprinkler with the nozzle-dispersion device can offer superior advantage of a larger spray range for better overlap and disperse more droplets for better 
Uniformity under low pressure conditions.

Subject: Agriculture

Keywords: Water dispersion devices, spray range, spray angle, impact sprinkler, R33 sprinkle

\section{Introduction}

Sprinklers depend on sprays to change continuous jet flow into droplets for uniform pattern distribution in a large range. This involves breakup of the jet into droplets of variable sizes. Several ways can be used to facilitate the breakup of jet, for example by high velocity air, and the application of external mechanical energy through a rotating or vibrating device (Lefebvre, 1989; Li et al., 2006; Nasr et al., 2006). Previous studies on various designs onspray devices have given a better understanding of performance and the resulting spray characteristics in different fields (Avulapati \& Venkata, 2013; Jiang et al., 2014; Kourmatzis \& Masri, 2015; Jadidi, et al., 2016; Strasser \& Battaglia, 2017). These devices are very significant to the development and characteristics of sprays for irrigation sprinklers.

Sprays develop from low velocity as a thin distorted stream under low pressure conditions. However, when the pressure is more than the ambient pressure, the jet forms a high velocity jet and degenerates quickly into droplets (Squire, 1953; Hagerty \& Shea, 1955; Gavaises \& Arcoumanis, 2001; Halder et al., 2002). Sprays from mechanical devices produces a cone angle of the spray. Improper configurations of nozzles, insufficient overlapping of sprays, and environmental conditions are the main factors that can affect the distribution pattern uniformity under irrigation sprinklers (Langenakens et al., 1999; Womac et al., 2001; Jeon et al., 2004). Only a small amount of the total spray volume impacts the crop, the remaining are lost as runoff and evaporation (Ebert et al. 1999; Dorr et al., 2013). A study conducted by Azimi et al. (1985) showed that the commonly used nozzle spacings, heights, and oworking pressures often produce marginal satisfactory distribution pattern uniformity. Other researchers studied spray distribution uniformity of nozzles on a boom but reported no statistical comparisons. The transverse distribution in volume or mass of over an area transverse to the direction of travel and the spray angle is related to angle formed close to the nozzle by the edges of the spray (ISO 5681, 1992).

Coefficient of variation can be used as performance indicator for evaluating the differences in the spray uniformity, and the values must be $15 \%$ or less (Etheridge et al., 1999; Herbst \& Wolf, 2001; Subr et al., 2017). The variation coefficient is affected by the working pressure and the way of spray dispersion of the jet by nozzle and dispersion devices (Al Gadi, 1998, 2010; 
Drocas, 2009). A variation coefficient of less than $7 \%$ has superior uniformity of distribution, and this value gives a satisfactory uniformity. But, the values of coefficient of variation from indoor experiments are generally smaller than the value which was measured under the field conditions (Smith, 1992). According to ISO 16122-2 (2015) standard, the threshold for the uniformity of the spray distribution within the total overlapped spacing must have a coefficient of variation $10 \%$ or less.

Overlapping of sprinklers is affected by the spray angle which, in turn, is affected by the working pressure. In this study, we investigated the effect of nozzle-dispersion device combination on pattern uniformity and defined mathematical models of the changes in variation coefficient for impact and R33 sprinklers. Because of their structure and external mechanical devices, their combined effect need to be completely overlapped and studied to gain the best spray distribution uniformity pattern.

\section{Materials and Methods}

Structure of R33 sprinkler

Low pressure version of the R33 sprinkler (3/16-inch) from Nelson Irrigation, Walla Walla, USA was used for the experiment (Fig. 1). The working pressure range of the R33 is from 150 to $350 \mathrm{kPa}$. When water flows through the distorted channel inside the nozzle, a driving force is generated due to the deflected angle in the channel. The nozzle rotates continuously at low speed due to the driving force from the channel and the resistance of the damping structure ( $\mathrm{Li}$ et al., 2016). The rotating dispersion device is a plate with a number of meshing teeth on the inner circle and several dispersion teeth on the outer circle. The inner teeth of the device mesh with a gear fixed on the center shaft of the sprinkler. Because of the meshing design, the water dispersion device rotates through the angle between adjacent inner gear teeth when the spray nozzle completes a full circle. The outlet diameter of the nozzle was $4 \mathrm{~mm}$ with an $18^{\circ}$ elevation angle. The depth of the dispersion tooth in the jet $(d)$ was $0.4 \mathrm{~mm}$, which was determined by the relation between the side impact angle $(\beta)$ of dispersion tooth was $60^{\circ}$ and width of tooth $(w)$ was 0.1 $\mathrm{mm}$, while the distance (c) from the nozzle to the dispersion tooth was $4.0 \mathrm{~mm}$. 

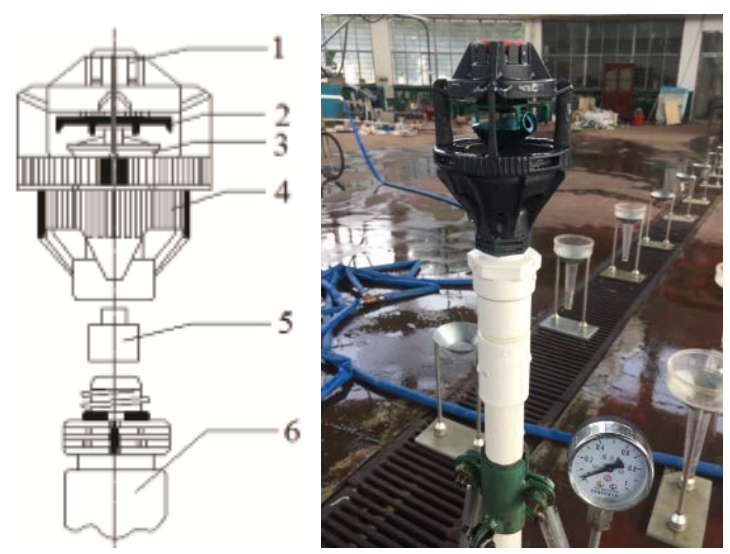

Figure 1. Structure of R33 sprinkler: 1. damping structure,2.

water dispersion device, 3. sprinkler nozzle, 4. body, 5. nozzle, and 6. connector.

Figure 2 gives a schematic diagram of the rotating apron plate structure. The apron plate is a key component to achieve uniform water distribution for R33 sprinkler. Using the supplement method near the nozzle, the sprinkler can deliver water in the whole spraying area after rotating several circles. The apron plate installed on the spray tray is an eccentric gear meshing with the central shaft, which is a circular sheet, with several triangular shaped meshing teeth inside, a multiple apron tooth outside.

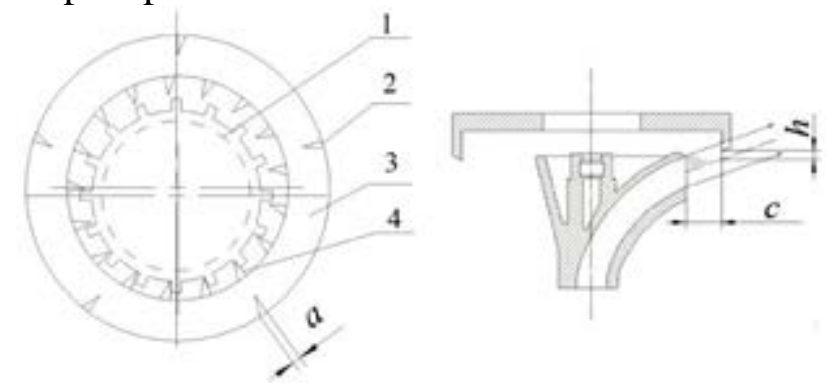

Figure 2. Structure of the water dispersion device: 1. gear fixed on the center shaft, 2. dispersion tooth, 3. Rotating plate, and 4. inner tooth; $a$ is width of dispersion tooth, $h$ is insertion depth of dispersion tooth into water jet, and $c$ is distance between the nozzle and dispersion tooth.

The process of apron plate is also the process of apron plate realizes jumping state from the meshing state with the gear, which can be divided into meshing stage, off stage and gear jumping stage, using the tooth $\mathrm{A}_{1}$ and $\mathrm{B}_{1}$ as examples to illustrate the process of movement.

a. Meshing stage: when the first tooth is impacted by the water flow, because of the flow reaction, gear $\mathrm{A}_{1}$ and $\mathrm{B}_{1}$ move into meshing stage, whiles gears $A_{2}$ and $B_{2}$ goes into off-stage, as shown in Fig. 3a.

$b$. Off-stage: when the water rotated to the position of tooth apron3, before it was impacted by water flow, $\mathrm{A}_{2}$ and $\mathrm{B}_{2}$ are off-stage; after 
impacted by water flow, the apron plate is rotated to a certain angle, to achieve the removal of teeth $A_{1}$ and $B_{1}$. At this point, the tooth $A_{2}$ and $B_{2}$ change from the original off state to the jump state, as shown in Fig. $3 \mathbf{b}$.

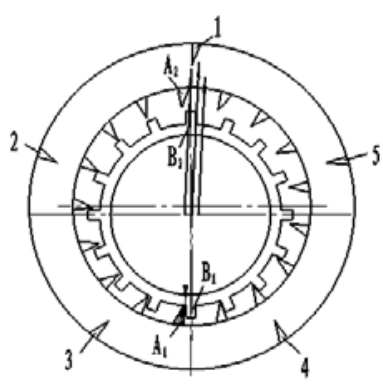

Cra

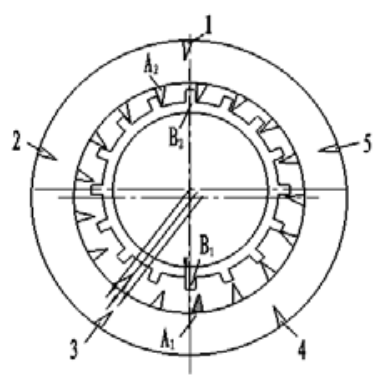

a

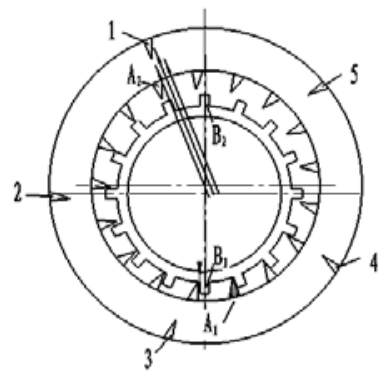

b

Figure 3. Movement of the rotating plate: a meshing stage, $\mathbf{b}$ off-stage, $\mathbf{c}$ jumping state.

c. Jumping stage: when the sprinkler rotates a circle, which means that water flows again to position apron tooth, the teeth $\mathrm{A}_{1}$ and $\mathrm{B}_{1}$ are in the dislocation state before they are impacted by the water flow; after the impact of the water flow, the sprinkler is rotated by an angle to realize the jump of the teeth $A_{1}$ and $B_{1}$, as shown in Fig. 3c.Thesprinkler completes one cycle after the three stages to achieve a grid of scattered plate rotation, a grid of rotation angle is the angle between the adjacent teeth.

\section{Impact sprinkler with fixed dispersion device}

Impact sprinkler (1-inch) from Davide and Luigi Volpi Spa, Casalromano (CM), Italy was used for the experiment (Fig. 4). The recommended working pressure for the sprinkler is between $250-300 \mathrm{kPa}$. In this study, pointed and flat tip profiles of the fixed water dispersion device were considered. Impact sprinkler operates by spraying pressurized water from a newly designed nozzle with inlet and outlet diameters of 18 and $6 \mathrm{~mm}$, respectively and the elevation angle was $25^{\circ}$. A hole was drilled in the arm and threaded according to the diameter of the dispersion device to accept it in position. The dispersion arm was first screwed to the sprinkler, and a new type of fixed dispersion device was inserted into a spring and screwed into the holder with a depth of $4.5 \mathrm{~mm}$ protruding into the jet flow (Fig. 5). The complete arrangement was mounted on the sprinkler using a screw. As the jet flows from the nozzle and impact on the deflector, the sprinkler is driven into rotation. The deflector arm is repeatedly pushed back into the jet flow by a spring-loaded arm each time it meets the jet flow. 


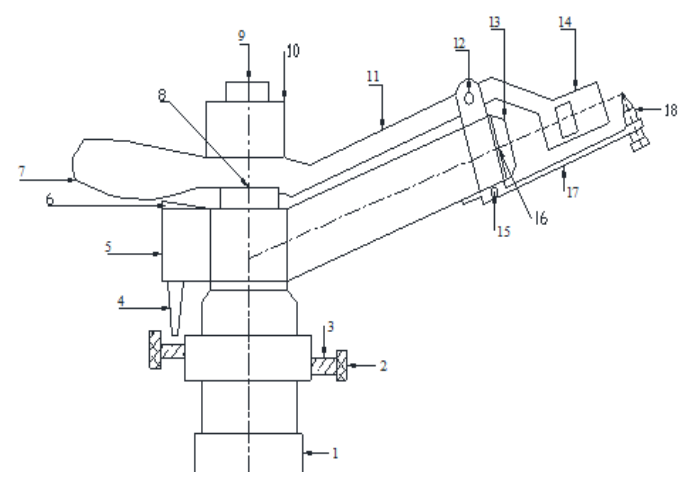

Figure 4. Structural diagram of the impact sprinkler:1. bearing assemble 2. shift lever 3. spring 4. snap level 5. swing level 5. stop shifter 6. casing lever 7. backarm8. bearing assemble 9. inverted U-shaped mounting structure 10. sprinkler head body 11. impulse arm 12. screw for arm 13. nozzle 14. deflector 15. screw for device 16. nozzle assembly 17. holder for the dispersion device 18. fixed water dispersion device.

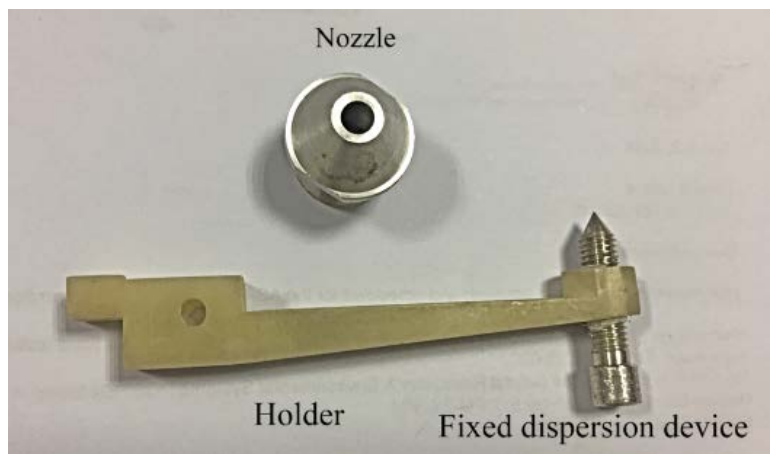

Figure 5. Prototypes of nozzle, fixed dispersion and holder devices for the impact sprinkler

The spring provides vertical stability to the fixed water dispersion device during jet flow impact. The tip of the dispersion device protrudes into the jet flow, and as the jet impinged the fixed dispersion device, the flow was interrupted which caused a change in linear momentum, and the jet finally break up and dispersed. As a result, the inertia and momentum of the droplets are decreased, and the droplets fall near to the sprinkler.

Table 1. Basic parameters of the two sprinkler types

\begin{tabular}{ccccc}
\hline Type & $\begin{array}{c}\text { Nozzle shape } \\
(\mathrm{mm})\end{array}$ & $\begin{array}{c}\text { Diameter } \\
(\mathrm{mm})\end{array}$ & $\begin{array}{c}\text { Elevation } \\
\text { angle }\left({ }^{\circ}\right)\end{array}$ & $\begin{array}{c}\text { Depth of device in } \\
\text { jet }(\mathrm{mm})\end{array}$ \\
\hline $\begin{array}{c}\text { R33 sprinkler } \\
\text { Impact }\end{array}$ & Elliptical & 3.8 & 18 & 0.4 \\
sprinkler & Circular & 6 & 23 & 4.5 \\
\hline
\end{tabular}

In summary, the basic parameters of two sprinkler are listed in Table 1. The main differences between the sprinklers are that the R33 sprinkler has a distorted channel and is equipped with a $3.8 \mathrm{~mm}$ ellipse type nozzle, while the 
impact sprinkler had a $6 \mathrm{~mm}$ circular type nozzle. The sprinkler jet forms $18^{\circ}$ angle for the R33 and $23^{\circ}$ for the impact sprinkler with respect to the horizontal. Additionally, the R33 is equipped with a rotating plate with a number of water dispersion teeth, while the impact sprinkler had a fixed dispersion device mounted.

\section{Jet dispersion theory for $\mathrm{R} 33$ sprinkler}

As presented in Fig. 6, the dispersion process involves the development of spray from the jet upon impingement on the water dispersion teeth, and then the formation of droplets (Li \& Kawano, 1994). Spray coverage gives the spray angle that it is regarded as the starting point for the calculation.

a. Spray angle $(\theta)$ : angle of the spray measured close to the nozzle, because the droplets are impacted by external forces such as gravity and surrounding air.

b. Actual spray coverage (A): actual coverage at a specified distance, $x$ from the nozzle.

c. Effective spray angle (B): angle calculated from the Bat a distance, $x$.

d. Theoretical spray coverage (C): coverage at distance, $x$ if the spray moved in a straight line.

The spray angle widens in relation to the vertical axis, which tends to reduce or increase with the increase of distance from the point of spray as illustrated in the figure below. And the spray coverage was different as the angle of dispersion changes. The distance where the velocity is Zero, indicates the distance where the velocity attained half the axial velocity is of greater value (Zhu et al., 2012). Four terms are commonly used to describe spray coverage:

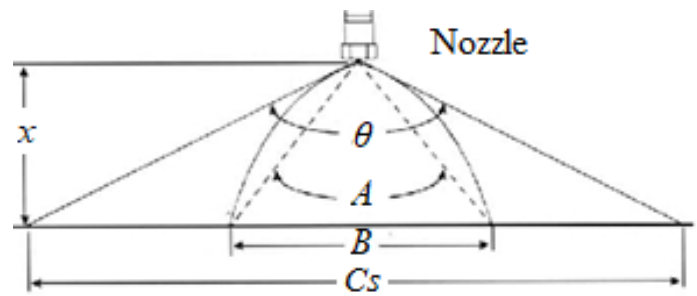

Figure 6. Schematic model of water jet: $y$ is the depth of the fixed water dispersion device in jet (mm), $x$ is the specified axial spray distance (mm), $\theta$ is the spray angleB is effective spay angle $\left({ }^{\circ}\right), C_{s}$ is theoretical spray coverage $(\mathrm{mm}), r_{1 / 2}$ is the radial location where the jet velocity has decayed to half of centerline value.

Jet dispersion theory for impact sprinkler

As presented in Fig. 7, the Initial breakup process involves the breakup of the jet flow from the nozzle upon impingement on the dispersion device, and secondary breakup describes the final breakdown of droplets. The spray angle diverges in relation to the vertical axis. As illustrated in the figure below, the spray angle tends to reduce or increase with the increase of distance from 
the point of spray. Spray coverage was different as the angle of dispersion changes. The distance where the velocity is Zero, the distance where the velocity attained half the axial velocity is of greater. The spray coverage at specific distances for angles below $180^{\circ}$ were calculated using the formula (3) below.

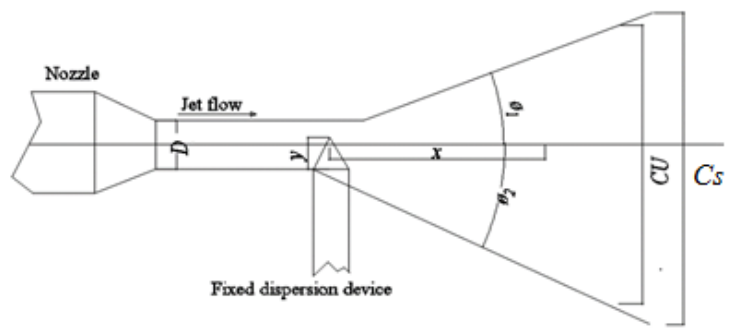

Figure 7. Schematic model of jet impact on the fixed water dispersion device: $R$ is the spray range $(\mathrm{m}), y$ is the depth of the fixed water dispersion device in jet $(\mathrm{mm}), \theta\left(\theta_{1}+\theta_{2}\right)$ is spray angle, $U$ is uniformity (\%), $C_{s}$ is the spray coverage $(\mathrm{mm}), r_{1 / 2}$ is the radial location where jet velocity has decayed to half of centerline value.

\section{Measurement of spray range and water distributions}

Catch cans were spaced $1 \mathrm{~m}$ apart with a uniform angle, and the sprinkler position was used as the center. The distance from the point with irrigation intensity of $0.3 \mathrm{~mm} / \mathrm{h}$ (the point with irrigation intensity of $0.15 \mathrm{~mm} / \mathrm{h}$ when the flow is below $0.25 \mathrm{~m}^{3} / \mathrm{h}$ ) to the center of sprinkler was defined as the sprinkler range (Kotsovinos, 1976; ASABE, 2007). The test duration was one hour. All measurements were repeated three times, with the average value taken as the sprinkler application rate.

\section{Photographic technique}

Figure 8 shows arrangement of equipment in the photographic experimental system. The camera light was used to produce the straight beam. The sprinkler was fixed in one-direction, and a high-speed camera was set to $0.1 \mathrm{~ms}$ for each frame in the test, while the exposure time was set as $5 \mu$ s. For the shadow method, the optical system consisted of a $1000 \mathrm{~W}$ camera light and a piece of ground glass. The light went through the jet flow while flow fluctuates, then a shadow image of jet and surface wave was captured by the camera. The ground glass was used to attenuate the light. To capture clearer images, a $100 \mathrm{~mm}$ micro-lens was configured on the camera. A dark material was placed at the back of the jet area, and the jet flow was illuminated by the light horizontal to the area captured. 


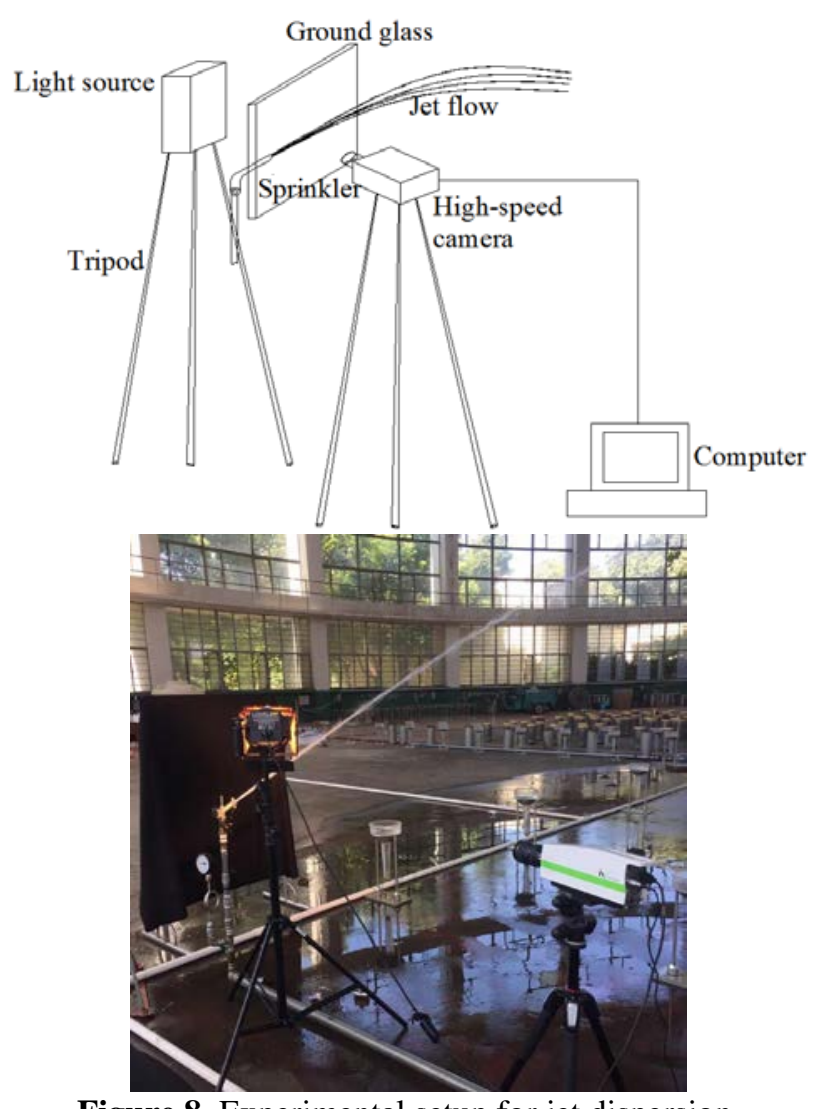

Figure 8. Experimental setup for jet dispersion.

The pressure in the laboratory was $100 \mathrm{kPa}$, while the working pressure was from 100 to $200 \mathrm{kPa}$. In this study, the effect of the water dispersion devices on spray angle and dispersion of the droplets was captured using the high-speed photography for further analysis. The conditions of water and air used in the experiment are listed in Table 2.

Table 2. Parameters of water and air used in experiment

\begin{tabular}{cc}
\hline Parameter & Value \\
\hline Temperature in Lab $/{ }^{\circ} \mathrm{C}$ & 20 \\
Density of water $/ \mathrm{kg} \cdot \mathrm{m}^{-3}$ & 998 \\
Viscosity $/ \mathrm{kg} \cdot(\mathrm{m} \cdot \mathrm{s})^{-1}$ & $1.01 \times 10^{-3}$ \\
Density of air $/ \mathrm{kg} \cdot \mathrm{m}-3$ & 1.293 \\
Viscosity of air $/ \mathrm{kg} \cdot(\mathrm{m} \cdot \mathrm{s})^{-1}$ & $1.79 \times 10^{-5}$ \\
Surface tension of water $/ \mathrm{N} \cdot \mathrm{m}^{-1}$ & 0.072 \\
Velocity air $/ \mathrm{m} \cdot \mathrm{s}^{-1}$ & $0.1-0.5$ \\
\hline
\end{tabular}

\section{Performance indexes}

Boundaries of the jet were demarcated and the angle between the boundaries and centerline was specified as the spray angle (Gregory \& 
Alarecon, 2008). It affects the water distributions and range in sprinkler irrigation. The calculation formula for spray angle is given as;

$$
\theta=\tan ^{-1}\left[\frac{r_{1 / 2}}{x}\right]
$$

Figure 9 presents the development of a mathematical model using Matrix Laboratory (MatLab) computation software program as given in equation 2 below. The different photographs captured during the experiments were applied into the computation program and the spray angles at different distances and pressures were computed.

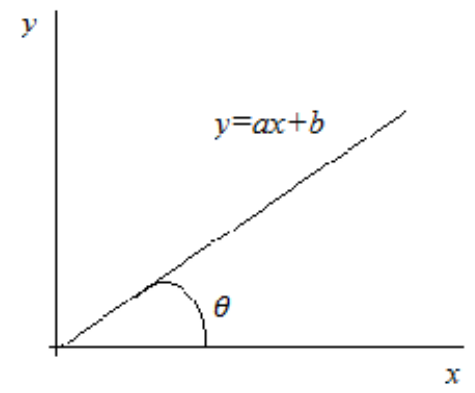

Figure 9. Mathematical of spray angle affected by dispersion device.

$$
\theta=\operatorname{atan}\left[\operatorname{abs}\left(\frac{a-b}{1+a+a b}\right) \times \frac{180}{\pi}\right]
$$

Spray coverage or spreading rate refers to the ratio of the jet half-width to the axial distance. It reflects the degree of water distribution, and its significance on the growth of crops is a measure of the quality of sprinkler irrigation. The calculating formula for spray coverage is given as;

$C_{s}=2 x \tan \left(\frac{\theta}{2}\right)$

where $C_{s}$ is spray coverage $(\mathrm{mm})$, xis the specified axial spray distance through the centerline $(\mathrm{mm}), \theta$ is spray angle $\left({ }^{\circ}\right)$.

Sprinkler uniformity was calculated from the application rates using the Christiansen uniformity coefficient in a square layout using equation (5). The measurement area of the application rate was completed in a matrix $(u \times v$ matrix: $\left.E=\left[e_{i j}\right] u \times v\right)$. If four sprinklers have application rates of $A, B, C$, and $D$, then their corresponding matrices are $a_{i j}, b_{i j}, c_{i j}$ and $d_{i j}$. Hence, the application rate from the catch cans $\left(e_{i j}\right)$ for the sprinkler is given as;

$$
e_{i j}+b_{i j}+c_{i j}+d_{i j}(1 \leq i \leq n ; 1 \leq j n)
$$

The coefficient of variation was used to evaluate the uniformities based on the ratio of the standard deviation of the water application rate from the catch cans under the sprinkler to the mean value of total water application rate (ISO 16122-2, 2015).

$$
C U=\left\{\frac{1-\sum_{i=1}^{n} \sum_{j=1}^{n}\left|e_{i j}-\frac{1}{n} \sum_{i=1}^{n} \sum_{j=1}^{n} e_{i j}\right|}{\sum_{i=1}^{n} \sum_{j=1}^{n} e_{i j}}\right\} \times 100 \%
$$




$$
\begin{gathered}
S D=\sqrt{1 /(n-1) \sum_{i=1}^{n}\left(x_{e i j}-\bar{x}\right)^{2}} \\
C V=\frac{\sigma}{\bar{x}}
\end{gathered}
$$

where $C U$ is spray distribution uniformity (\%), $C V$ is coefficient of variation, $e_{i j}$ is application rate from the catch can $(\mathrm{mm} / \mathrm{h}), \bar{x}$ is the mean water application rate collected in all catch cans $(\mathrm{mm} / \mathrm{h}), n$ is total number of catch cans, $S D$ is standard deviation, $u$ is the number of rows, and $v$ is the number of columns.

\section{Results and discussion}

Comparison of spay range

The effect of the water dispersion devices on spray range was examined by comparing the mean values under different working pressures conditions. As expected, the spray range increased with the increase of working pressure, and the largest spray ranges were produced from the sprinkler without a water dispersion device (Table 3). For example, the spray range from the R33 sprinkler without a water dispersion tooth was $14.6 \mathrm{~m}$, which was reduced by $14.0 \%$ after the water jet was interrupted by a dispersion tooth under a pressure of $150 \mathrm{kPa}$. An obvious reason could be that the jet travelled at a longer distance because it flowed freely through the empty space between two teeth of the apron rotating plate.

\begin{tabular}{|c|c|c|c|c|c|c|c|}
\hline \multirow[t]{2}{*}{ Type } & \multicolumn{4}{|c|}{ R33 sprinkler } & \multicolumn{3}{|c|}{ Impact sprinkler } \\
\hline & $\mathrm{kPa}$ & 100 & 150 & 200 & 100 & 150 & 200 \\
\hline No dispersion device & & 12.2 & 14.6 & 15.7 & 14.1 & 15.4 & 16.7 \\
\hline $\begin{array}{l}\text { With dispersion } \\
\text { device }\end{array}$ & & 11.1 & 12.4 & 13.6 & 13.6 & 14.2 & 16.1 \\
\hline
\end{tabular}

Table 3. Spray ranges for impact and R33 sprinklers under different pressures

Meanwhile, the spray from the impact sprinkler was only reduced by $8.4 \%$, which was $12.5 \%$ larger than the spray ranges from the R33 sprinkler. It was found that the spray from the impact sprinkler was only reduced by $8.4 \%$, which was $12.5 \%$ larger than that from the R33 sprinkler. The spray ranges were dependent upon the diameter of the cylindrical water jet between the nozzle and the water dispersion device, which affected the degree of interuption causing a small reduction in distance travelled by the water jet.

\section{Characteristics of spray}

Selected photographs of spray distribution when spraying with and without the water dispersion device under different working pressures are shown in Fig. 10. The surface boundaries of the water jet from both sprinklers was rough and similar, which increased with the increase of pressure(Fig. 
$10 \mathbf{a a n d} \mathbf{b}$ ).Figures 10c and 10d clearly indicates that the spray distribution was much better for both sprinklers after the water jet was interrupted by the dispersion device. Upon impingement of the water jet on the dispersion device, the surface tension was broken, producing a wide spray angle and a number of droplets can be seen in the observation area. The divergence or spreading of the water jet started progressively near the outlet of the nozzle as a mixture of air-water, which increased with increasing working pressure. Although the spray angle from the R33 sprinkler was larger, but the impact sprinkler appears to produce greater number of droplets below the spray (Fig. $10 \mathbf{c}$ and $\mathbf{d}$ ).This finding conforms to previous studies on the effect of working pressure on spray angle (Bradley et al. 2013; Edling 1985).

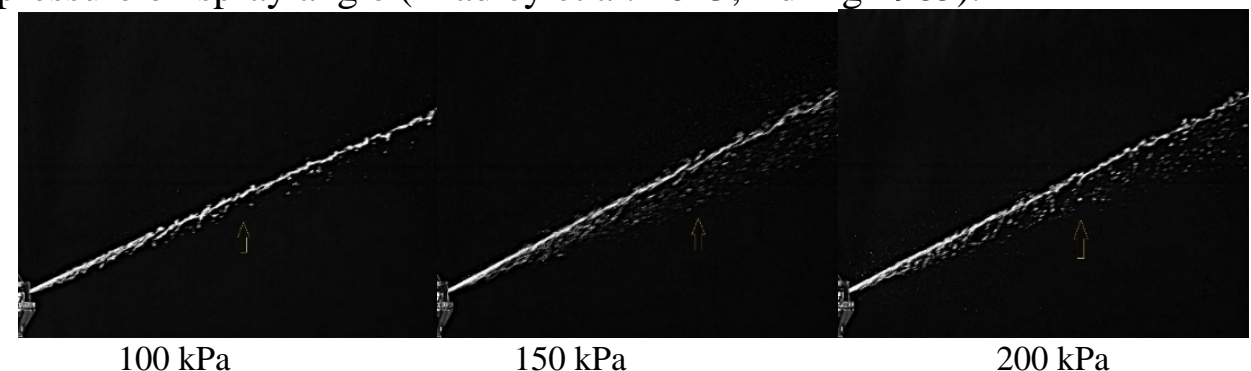

a. Jet from sprinkler without water dispersion tooth.

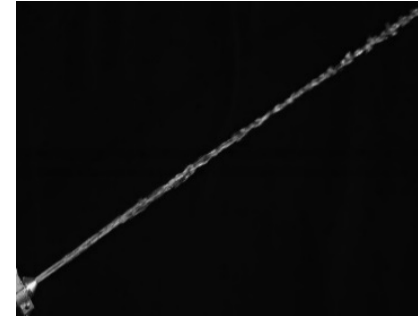

$100 \mathrm{kPa}$

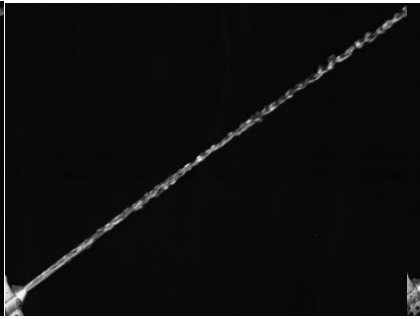

$150 \mathrm{kPa}$

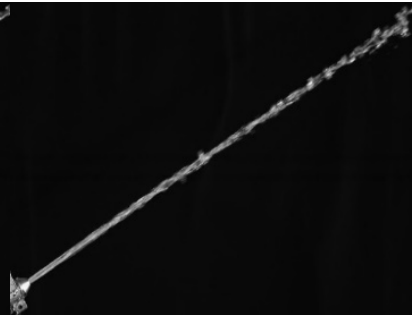

$200 \mathrm{kPa}$

b. Jet from sprinkler without fixed water dispersion device.

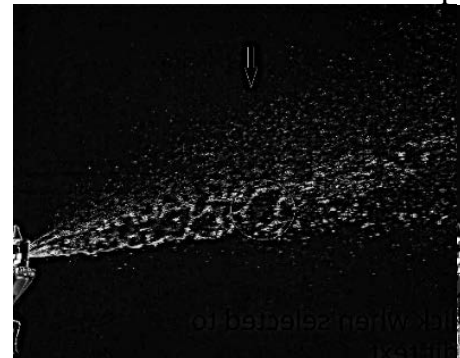

$100 \mathrm{kPa}$

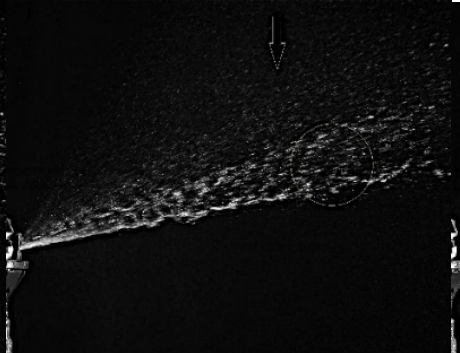

$150 \mathrm{kPa}$

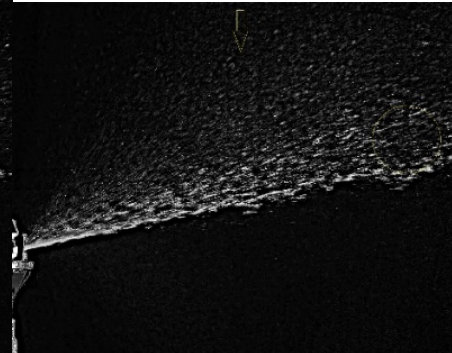

$200 \mathrm{kPa}$

c. Jet from R33 sprinkler with water dispersion tooth. 


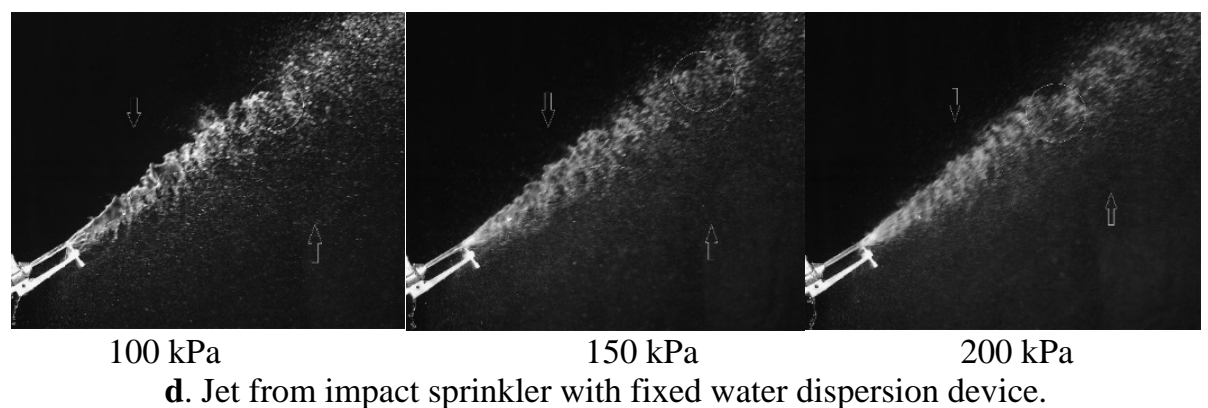

Figure 10. Jet from sprinkler without and with water dispersion tooth under different pressures.

The entrainment of air in the nozzle and surrounding tend to decrease the sizes of the droplets. In the case of R33 sprinkler, water flowed through the twisted channel at a deflected angle and impinged on a dispersion tooth, which was projected into the water jet outside forming a spray. The deflected surface in the nozzle of R33 sprinkler allows the formation of larger spray angles. Because there was no entrainment of air in the nozzle, the droplets sizes from the impact sprinkler seems larger, which could be useful to minimize the effect of wind and evaporation losses for the impact sprinkler, particularly under field conditions. However, further study on optimum droplet sizes are required to confirm this finding, because the kinetic energy of such droplets are greater and can cause crusts and erosion when transferred to the soil surface (Hamid et al. 2011; Bradley et al. 2013).

Spray angle

As presented in Fig. 11, the R33 sprinkler produced a large spray angle which increased from 34.1 to $48.4^{\circ}$ as the pressure was increased. Similarly, the spray angle from the impact sprinkler with the fixed water dispersion device ranged from 36.2 to $54.0^{\circ}$. Statistical analysis between the two sprinklers showed insignificant difference $(\mathrm{p}<0.05)$ in the spray angles under the pressures of 100 and $150 \mathrm{kPa}$. Smaller nozzle diameters such as the one used for the R33 sprinkler produces a larger spray angle. The depth of the tip of the fixed dispersion device in the water jet was larger, producing a spray angle similar to that of the R33 sprinklers. A large spray angle leads to early breakup and the effect produced by the horizontal component of the water jet momentum is beneficial for the dispersion and uniformity of sprinklers. 


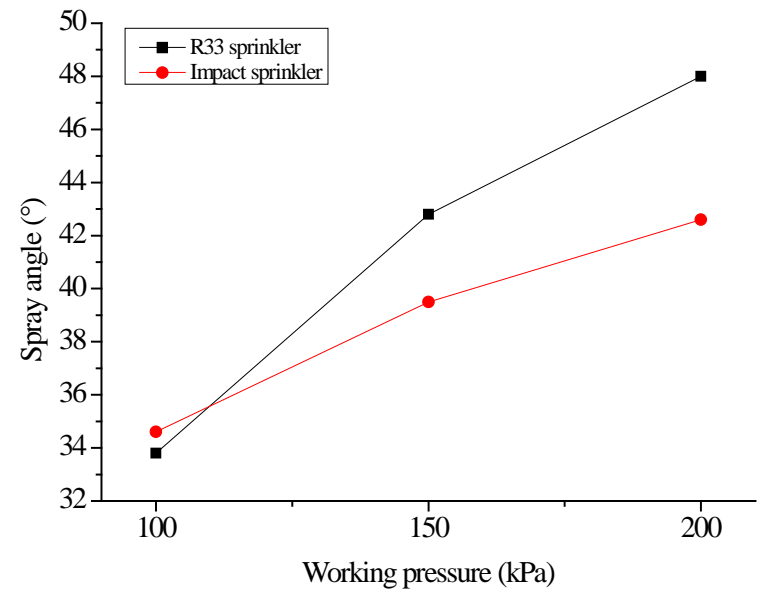

Figure 11.Relationship between spray angle and working pressure.

The relationship between the spray angle and working pressure was established for both sprinklers as specified below.

$$
\begin{aligned}
& y=0.38 x+25.14 ; R^{2}=0.982 \\
& y=0.63 x+28.78 ; R^{2}=0.977
\end{aligned}
$$

The coefficient of determination was $98.2 \%$ and $97.7 \%$ for the R33 and impact sprinklers, respectively, which gives an indication that the relationship was almost linear.

Spray coverage

Table 4 lists the theoretical coverage of spray patterns as calculated from the spray angle of the spray and the distance, $x$ from the nozzle of the sprinkler by using equation 3 . The values obtained were based on the assumption that the spray angle remains the same during the entire spray distance. However, this does not hold in actual practice for long spray distance. As can be seen, the spray coverage increased as the working pressure was increased. The R33 sprinkler produced the largest spray coverage which ranged from 767.72$1919.32 \mathrm{~mm}$ with a mean value of $1343.52 \mathrm{~mm}$, while that from the impact sprinkler range from 688.65-1721.63 and the mean value of was $1205.14 \mathrm{~mm}$ at the same distance from the nozzle. Statistical analyses showed no significant difference $(p<0.05)$ between the two sprinklers under the same pressure conditions.

Table 4. Comparison of spray coverages ( $\mathrm{mm}$ ) for the sprinklers under different pressures.

\begin{tabular}{ccccccccc}
\hline Distance, & \multicolumn{3}{c}{ R33 sprinkler } & & \multicolumn{3}{c}{ Impact sprinkler } \\
\cline { 2 - 4 } \cline { 7 - 9 }$x(\mathrm{~mm})$ & $\mathrm{kPa}$ & 100 & 150 & 200 & & 100 & 150 & 200 \\
\hline 1000 & 592.42 & 767.72 & 890.45 & & 611.46 & 688.65 & 767.72 \\
1500 & & 888.64 & 1151.59 & 1335.68 & & 917.19 & 1032.98 & 1151.59 \\
2000 & 1184.85 & 1535.45 & 1780.91 & & 1222.92 & 1377.31 & 1535.45 \\
2500 & & 1481.05 & 1919.32 & 2226.14 & & 1528.65 & 1721.63 & 1919.32 \\
\hline
\end{tabular}


Both sprinklers produced a large spray angle under the same pressure conditions, resulting greater spray coverage effect produced by the horizontal component of the water jet momentum is beneficial for the dispersion and uniformity of sprinklers.

Relationship between CVs of spray uniformity and pressure

The means and standard deviations listed in the Table 5 were derived from the simulated CUs for the sprinklers under different pressures. The effect of pressure on spray uniformity was evaluated by comparing the mean $\mathrm{CU}$ values for both sprinkler under three different pressure conditions. Mean simulated CUs from theR33 sprinkler was $78.18 \%$, while the impact sprinkler gave a mean CU value of76.73\% under a low pressure of $150 \mathrm{kPa}$. With the increase of working pressure, the mean CUs increased slightly for both sprinklers. In this study, ANOVA analysis showed that the difference in CUs for both sprinkler was not statistically not significant $(\mathrm{p}<0.05)$ under low pressure conditions. These values were expected because we had more droplets produced from the impact sprinkler which fell at a distance close to sprinkler the upon impingement on the fixed dispersion device as can be observed in Fig. 10d.

Table 5. Basic statistics of uniformity for the sprinklers under different pressures

\begin{tabular}{|c|c|c|c|c|c|c|}
\hline \multirow{2}{*}{$\begin{array}{l}\text { Pressure } \\
(\mathrm{kPa})\end{array}$} & \multicolumn{3}{|c|}{ R33 sprinkler } & \multicolumn{3}{|c|}{ Impact sprinkler } \\
\hline & Mean (\%) & SD (\%) & CV (\%) & Mean (\%) & SD (\%) & CV (\%) \\
\hline 100 & 69.41 & 0.92 & 2.8 & 67.62 & 1.44 & 3.4 \\
\hline 150 & 76.73 & 0.78 & 4.1 & 78.18 & 0.96 & 2.5 \\
\hline 200 & 78.95 & 0.65 & 5.4 & 81.04 & 0.73 & 2.1 \\
\hline
\end{tabular}

It can be seen in Fig. 12that the CV values for both sprinklers decreased as the working pressure was increased and finally coincided under a pressure of $200 \mathrm{kPa}$. The CV values were less than $10 \%$ and within the acceptable levels when using the pressures of 150 and $200 \mathrm{kPa}$ for the test. Both sprinkler had poor $\mathrm{CV}$ values of more than $10 \%$ as the working pressure was decreased to $100 \mathrm{kPa}$, which could be the results from the effect of spray angle which was smaller due to the unsatisfactory working pressure. This means that there is a specific pressure for the nozzle-dispersion device combination where the $\mathrm{CV}$ value reaches the lowest value for the impact sprinkler. A study of the spray uniformity from agricultural nozzles found that the CV values ranged from 12.1-22.6\% (Etheridge et al., 1999). 


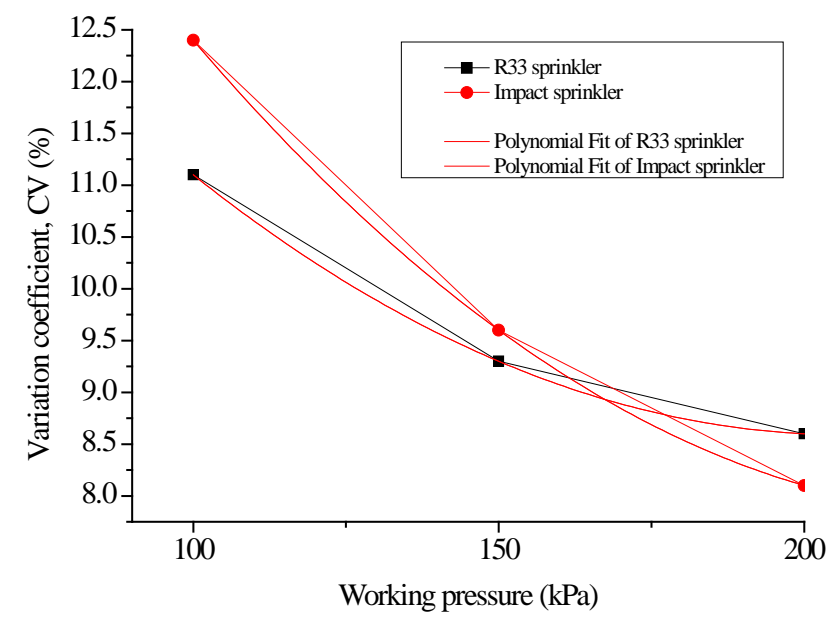

Fig. 12. Relationship between CVs of spray uniformity and pressures.

For a given pressure values, $x$, we get the coefficient of variation given sprinkler. Using the combination of nozzle-dispersion device on the impact sprinkler gives the famer the ability to obtain an application parameter that provides quality spray pattern distribution. This prevents the possibility of poor uniformity and waste of irrigation water. Mathematical models of changes in the coefficient of variation depending on the change in pressure are given in equations (9 and 10) for R33 and impact sprinklers, respectively:

$y=0.0002 x^{2}-0.112 x+21.2 ; R^{2} 0.9881$

$y=0.0002 x^{2}-0.091 x+18 ; R^{2} 0.9793$

Figure 9 presents the relationship between degree of spray nonuniformity and pressure. In this respect, the degree of non-uniformity values was $22.27 \%$ for the R33 sprinkler, whereas the impact sprinkler was slightly higher with a value of $25.51 \%$. This may suggest that the combined effect of the nozzle-dispersion device could be useful to improve the quality in distribution pattern uniformity of sprays for the impact sprinkler under lowpressure conditions. The study reveals a decreasing trend of non-uniformity with the increase of pressure for both sprinklers. 


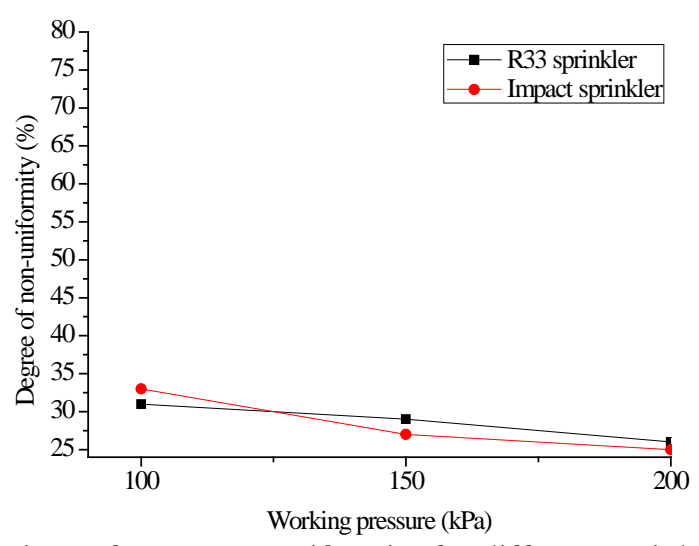

Figure 13. Comparison of spray non-uniformity for different sprinklers and pressures.

Because the degree of non-uniformity for the impact sprinkler was similar to that of the R33 sprinkler, hence the combined effect of nozzledispersion device in improvement of spray uniformity appears to be more suitable to be used under low-pressure conditions in this time of the rising energy costs.

\section{Conclusions}

From the results within the scope of comparison of the spray distribution pattern uniformity for impact sprinkler with the fixed dispersion-nozzle device and R33 sprinkler, the following can be concluded:

1. For the same working pressure of $150 \mathrm{kPa}$, the impact sprinkler had the advantage of a large spray pattern range that was $12.6 \%$ larger than the range from the R33 sprinkler.

2. Spray characteristics for the impact sprinkler were similar to those produced by the R33 sprinkler and the number of droplets increased with increasing spray angle due to early breakup which is beneficial for greater dispersion and uniformity of sprinklers.

3. Combination of the nozzle-dispersion device had a strong effect on minimizing the degree of spray non-uniformity for the impact sprinkler, and the CV values were less than $10 \%$. This result may suggest that the impact sprinkler was working efficiently as the R33 sprinkler by providing higher spray distribution pattern

4. uniformities.

\section{References:}

1. AL-Gaadi, KA. 1998. Effect of nozzle height and type on spray density and distribution for a ground field sprayer. In: Precision Farming Research Chair (PARC). Riyadh, Kingdom of Saudi Arabia: King Saud University, 
2. AL-Gaadi, KA. 2010. Effect of nozzle height and type on spray density and distribution for a ground field sprayer. J. Saudi Soc. for Agric. Sci., 9(1): 1-12.

3. American Society of Agricultural and Biological Engineers 2007. ASABE Standards (R2007). S398.1: Procedure for sprinkler testing and performance reporting. St Joseph, Mich., MI. USA.

4. Avulapati, MM, \& Ravikrishna, R. 2015. Experimental studies on airassisted atomization of Jatropha pure plant oil. Atomization and Sprays,25(7).

5. Azimi, HA, Carpenter, GT and Reichard, D. 1985. Nozzle Spray Distribution for Pesticide Application. Transactions of the ASAE,28: $1410-1$

6. Drocas, A. 2009. Determination of distribution uniformity for EEP600 sprayer equiped with IDK 120-02 nozzle. Scientific papers USAMV Buchurest, Series A. Agronomy, 52: 304-309.

7. Dorr, GJ, Hewitt, AJ, Adkins, SW, Hanan, J, Zhang, H, and Noller, B. 2013. A comparison of initial spray characteristics produced by agricultural nozzles. Crop Protection,53(0): 109-117.

8. Ebert, TA, Taylor, RaJ, Downer, RA, and Hall, FR. 1999 Deposit structure and efficacy of pesticide application: Interactions between deposit size, toxicant concentration and deposit number. Pesticide Science, 55(8), 783-792.

9. Edling, R. J. 1985 Kinetic energy, evaporation and wind drift of droplets from low pressure irrigation nozzles. Transactions of the ASAE,28(5), 1543-1550.

10. Etheridge, RE, Womac, AR, and Mueller, TC. 1999 Characterization of the spray droplet spectra and patterns of four venturi-type drift reduction nozzles. Weed Technol, 13, 765-770.

11. Gavaises, M., C. Arcoumanis 2001. Modelling of sprays from highpressure swirl atomizers, Int. J. Engine Res.,12, 95-117.

12. Gregory, C. T. \& Alarecon, J. J. 2008Rotary sprinkler orifice for enhancing close-in water distribution. U.S. Patent No. 7325753B2.

13. Hagerty, W.W., and J.F. Shea (1955). A study of the stability of plane fluid sheets, J. Appl. Mech.22, 509-514.

14. Halder, M.R., S.K. Dash and S.K. Som 2002. Initiation of air core in a simplex nozzle and the effects of operation and geometrical parameters on its shape and size, Exp. Therm. Fluid Sci.26, 871-878.

15. Hamid, A. H. A., Atan, R. L., Noh, M. H. M. \& Rashid, H. 2011 Spray cone angle and air core diameter of hollow cone swirl rocket injector. IIUM Engineering Journal, Special Issue on Mechanical Engineering,12, 3. 
16. Herbst, A, and Wolf, P. 2001. Spray deposit distribution from agricultural boom sprayers in dynamic conditions. 2001 ASAE Annual Meeting, USA.

17. ISO 16122-2, 2015. Agricultural and forestry machinery: Inspection of sprayers in use-Part 2: Horizontal boom sprayers, 18.

18. Jadidi, M., Moghtadernejad, S., \& Dolatabadi, A. 2016. Penetration and breakup of liquid jet in transverse free air jet with application in suspension-solution thermal sprays. Materials \& Design, 110, 425435.

19. Jeon, HY, Womac, A, and Gunn, J. 2004. Sprayer boom dynamic effect on application uniformity. Transactions of ASAE,47(3), 647658.

20. Jiang, L., Agrawal, A. K., \& Taylor, R. P. 2014. Clean combustion of different liquid fuels using a novel injector. Experimental Thermal and Fluid Science, 57, 275-284.

21. Kotsovinos, N. E. A 1976Note on the spreading rate and virtual origin of a plane turbulent jet. Journal of Fluid Mechanics,77, 305-311.

22. Kourmatzis, A., \& Masri, A. (2015). Air-assisted atomization of liquid jets in varying levels of turbulence. Journal of Fluid Mechanics,764, 95-132.

23. Langenakens, JJ, Clijmans, L, Ramon, H, and De Baerdemaeker, J. 1999. The effects of vertical sprayer boom movements on the uniformity of spray distribution. Journal of Agricultural Engineering Research, 74(3), 281-291.

24. Luck, JD, Pitla, SK, Sama, MP, and Shearer, SA 2015. Flow, spray pattern, and droplet spectra characteristics of an electronically actuated variable-orifice nozzle. Transactions of the ASABE, 58(2), 261- 269.

25. Lefebvre, A. H. 1989 Atomization and sprays. Hemisphere Publishing Corporation, New York, USA.

26. Li, B.Q., Cader,T.,Schwarzkopf, J.,Okamoto, K. \& Ramaprian, B. 2006. Spray angle effect during spray cooling of microelectronics: experimental measurements and comparison with inverse calculations, Appl. Therm. Eng.,26, 1788-1795.

27. Li H, Jiang Y, Xu M, Li Y and Chen C. 2016 Effect on hydraulic performance of low-pressure sprinkler by an intermittent water dispersion device. Transactions of the ASABE,59(2): 521-532.

28. Nasr, G.G., R.A. Sharief and A.J. Yule 2006. High pressure spray cooling of a moving surface, J. Heat Transfer, 12(8),752-760.

29. Subr A, Milanowski M, Parafiniuk, S and Sawa, Józef 2017. Testing the uniformity of spray distribution under different application parameters. IX International Scientific Symposium "Farm Machinery 
and Processes Management in Sustainable Agriculture", Lublin, Poland.

30. Smith, D. B. 1992 Uniformity and recovery of broadcast sprays using fan nozzles,Transactions of the ASAE, 35(1): 39-44.

31. Squire, H.B. 1953 Investigation of the instability of a moving liquid film, Brit. J. Appl. Phys. 4, 167-169.

32. Strasser, W., \& Battaglia, F. 2017. The effects of pulsation and retraction on non-Newtonian flows in three-stream injector atomization systems. Chemical engineering journal, 309, 532-544.

33. Womac, A., Ethridge, R., A., S, Hogan, D.\& Ray, S. 2001 Sprayer speed and venturinozzle effects on broadcast application uniformity. Transactions of ASAE, 44(6), 1437-1444.

34. Zhu, X. Y., Yuan, S. Q. \& Liu, J. P. 2012 Effect of sprinkler head geometrical parameters on hydraulic performance of fluidic sprinkler. J Irrig Drain Eng ASCE,138(11), 1019-1026. 